\title{
INFLUENCE OF DIFFERENT COTTON VARIETIES AND GENOTYPES ON THE INFESTATION BY THE SPINY BOLLWORM Earias insulana (BOISD.)AT KAFR EL-SHEIKH GOVERNORATE \\ Somaa, H.M.H. and Asmaa M.A. El-Ghobary \\ Plant Protection Research Institute- Agric. Res. Center, Egypt
}

\begin{abstract}
The present work was carried out during two successive seasons (2012 and 2013) at Farm of Sakha Agricultural Research Station, Kafr El-Sheikh Governorate, Egypt to evaluate the influence of different cotton varieties and genotypes on the infestation by the spiny bollworm Earias insulana (Boisd.) at Kafr El-Sheikh Governorate. Results during the two experiments showed the infestation percentage of SBW to six cotton varieties and genotypes of both seasons were $(8.14,7.64,7.66,6.08,7.16$ and $8.36 \%)$ for Giza 86, Pima S6 x Giza 77, Giza 92, Giza 94, Giza 86 x 10/229 and Giza 88, respectively. The highest means of infestation \% were recorded in the G.88 and G.86 in both seasons, while the lowest means of infestation\% were recorded in the G.94 and G.86 x 10/229 in both seasons. The differences among means of infestation \% may be due to the differences of gossypol \% in wall thickness of green boll. The means of gossypol\% in green boll wall were $(1.78,1.32,1.440 .91,1.75$ and $1.16 \%)$ and the means of wall thickness were $(2.77$, 2.38, 2.07, $2.82,3.04$ and $2.94 \mathrm{~mm}$ ) for above cotton varieties and genotypes during both seasons, respectively. There were highly significant differences among the cotton varieties and genotypes in some characters.
\end{abstract}

\section{INTRODUCTION}

The Egyptian cotton lint is highly valued worldwide and is one of the major sources of foreign currency to the Egyptian national income. Cotton plants are subjected to attack by a wide range of insect pests throughout growing stages until near maturity. Spiny bollworm, is one of the most important pests of cotton and other crops in Egypt. This pest attacks the fruit bodies of cotton and cause heavy losses in the yield. This insect caused about $80 \%$ damage to cotton in south Khorrasan region of Iran (Fasell, 1977). So, far, the main method of controlling spiny bollworm on cotton has been the use of insecticides. Chemical control of this insect is expensive and serious peripheral problems have emerged, these include the development of insecticide-resistant insect strains, reduction of pest insect natural enemies, resurgence of pest populations in the absence of natural enemies, occurrence of secondary pests and environmental contamination. Therefore, it is strictly necessary to select resistant varieties as one of the simplest and useful tactics in integrated pest management programme. Differences in the susceptibility of cotton varieties to spiny bollworm infestation have been previously studied by Hassanein et al. (1969); Abd El-Rahim et al. (1976); Abdel-Bary et al. (1980); I Abdel-Halim et al. (2000); El-Mezayyen (2004)and Al-Ameer et al. (2010). Therefore, the present study was initiated to determine the relative susceptibility of six cotton varieties and genotypes to infestation by $E$. insulana under field agro-conditions. 


\section{MATERIALS AND METHODS}

Six Egyptian cotton varieties and genotypes were selected for this study namely: Giza 86, Pima S6 x Giza 77, Giza 92, Giza 94, Giza 86 x 10/229 and Giza 88. This experiment was conducted at Sakha Agricultural Research Station, Kafr El-Sheikh Governorate during two successive seasons 2012 and 2013 seasons.

Plot size measured $42 \mathrm{~m}^{2}$ (1/100 feddan) with three replicates for each variety and genotype arranged in a complete randomized block. Therefore, the experimental field contained 18 plots. Cotton was sown on March 29 2012 and March $20^{\text {th }}, 2013$, adopting the normal agricultural practices of irrigation and fertilization including three recommended insecticidal treatments as follows: $1^{\text {st }}$ treatment: applied in July with Sylian $72 \%$ EC (0-4-bromo-2-chlorophenyl-O-ethyl-S-propyl phosphorothioate) at rate of $750 \mathrm{~cm} /$ feddan, and Dimeuron 10\% EC, 1-[3,5-dichloro-4-(1,1,2,2tetra-fluoroethoxy) phenyl]-3-(2-6-difluorobenzoyl) urea, at rate of 200 $\mathrm{cm} /$ feddan, $2^{\text {nd }}$ treatment: in July and August (two weeks after the $1^{\text {st }}$ treatment) with killeforon 5\% EC (RS)-1-[2,5-dichloro-4-(1,1,2,3,3,3hexafluoroproxy) phenyl]3-(2,6-difluorobenzoyl), urea (at rate of 160 $\mathrm{cm} /$ feddan), and Cyperco 20\% EC (RS)-a-cyano-3-phenoxyl (1RS-3RS, 1RS3SR)-3-(2, 2-dichlorovinyl)2, 2-dimethyl cyclopropane carboxylate, (at rate of $150 \mathrm{~cm} /$ feddan), and $3^{\text {rd }}$ treatment: in August and September with Sylian $72 \%$ EC and Dimeuron 10\% EC. Every insecticide was sprayed at 2 weeks intervals starting from July using the recommended rate of the proper insecticide diluted with 400 liters water. All sprays were conducted using knapsack sprayer (CP3 model). Weekly random samples of 50 green bolls were collected from each plot (150 green bolls each variety) and kept in tightly closed polyethylene bags, then dissected and examined in the laboratory of Plant Protection Research Institute at Sakha, Kafr El-Sheikh from the second week of July until the second week of October. Percentages of infestation by spiny bollworm were determined in each cotton variety and genotype. So, cotton yield $\mathrm{g} / \mathrm{m}^{2}$ of each variety and genotype was evaluated. 40 bolls each variety and genotype samples for estimating gossypol ratio in green boll wall were analyzed in the chemical laboratory of Chemical Research Department, Cotton Research Institute in Giza. The actual measurement of green boll wall thickness in millimeters was done as the distance across the fertile lemma and palea at the widest point (IRRI Stand, 1996). The statistical analysis was conducted using the software programme MSTATC.

\section{RESULTS AND DISCUSSION}

\section{Inspections of infestation by spiny bollworm, Earias insulana in during the two seasons 2012 and 2013:}

Results in Table (1) show the mean numbers of infested green boll by SBW larvae per 50 bolls for each of six varieties and genotypes of cotton, mean number of infested bolls were $(5.28,3.57,4.22,3.71,3.29$ and 5.71 bolls) for G.86, Pima S6 x Giza 77, G. 92, G. 94, G. 86 x 10/229 and G.88, respectively. The highest mean numbers of infestation bolls during this 
season was estimated in G.88 and G.86 (5.71 and 5.28 bolls), respectively. While, the lowest was in G.86 x 10/229 and Pima S6 x G.77 (3.29 and 3.57 bolls), respectively.

Data presented in Table (2) indicate that the mean number of infested bolls by SBW larvae in season 2013 , were $(2.86,4.07,3.43,2.36,3.86$ and 2.64 bolls) for the same varieties and genotypes, respectively. The highest mean number of infested bolls during this season was estimated in Pima S6 $x$ G.77 and G.86 x 10/229 (4.07 and 3.86 bolls), respectively. While, the lowest was in G.94 and G.88 (2.36 and 2.64 bolls), respectively.

Table (1): Weekly mean number of infested green bolls by spiny bollworm, E. insulana (Boisd.) per $\mathbf{5 0}$ green bolls during season 2012.

\begin{tabular}{|l|c|c|c|c|c|c|}
\hline Variety & $\mathbf{G . 8 6}$ & $\begin{array}{c}\text { Pima S6 x } \\
\text { G.77 }\end{array}$ & $\mathbf{G . 9 2}$ & $\mathbf{G . 9 4}$ & $\begin{array}{c}\mathbf{G . 8 6} \mathbf{x} \\
\mathbf{1 0 / 2 2 9}\end{array}$ & $\mathbf{G . 8 8}$ \\
\hline $26 / 7$ & 0 & 0 & 0 & 0 & 0 & 0 \\
$2 / 8$ & 0 & 1 & 0 & 1 & 0 & 0 \\
$9 / 8$ & 1 & 1 & 0 & 0 & 0 & 1 \\
$16 / 8$ & 0 & 0 & 0 & 1 & 0 & 1 \\
$23 / 8$ & 1 & 1 & 0 & 0 & 0 & 0 \\
$30 / 8$ & 3 & 0 & 0 & 0 & 2 & 2 \\
$6 / 9$ & 2 & 2 & 3 & 1 & 3 & 2 \\
$13 / 9$ & 3 & 3 & 3 & 3 & 1 & 3 \\
$20 / 9$ & 3 & 7 & 6 & 4 & 3 & 6 \\
$27 / 9$ & 11 & 9 & 8 & 4 & 4 & 17 \\
$4 / 10$ & 11 & 8 & 12 & 11 & 10 & 14 \\
$11 / 10$ & 10 & 5 & 6 & 6 & 5 & 11 \\
$18 / 10$ & 18 & 7 & 12 & 17 & 11 & 18 \\
$25 / 10$ & 11 & 6 & 9 & 4 & 7 & 5 \\
\hline Total & 74 & 50 & 59 & 52 & 46 & 80 \\
\hline G.M. & 5.28 & 3.57 & 4.22 & 3.71 & 3.29 & 5.71 \\
\hline
\end{tabular}

General means of infested green bolls from six varieties and genotypes of cotton during both seasons:

In both seasons (2012 and 2013), data in table (3) show that the general means of infestation ratios were $(8.14,7.64,7.66,6.08,7.16$ and $8.36 \%)$. The highest and lowest average means of data over both seasons (8.36 and 8.14\%) and (6.08 and 7.16\%) for (G.88 and G.86) and (G.94 and G.86 x 10/229), respectively. Data in Table (4) indicate the insignificant differences among varieties and genotypes (0.99) and insignificant differences between years (10.86), but between varieties and years was significant differences $\left(3.34^{*}\right)$. Many authors found differences between varieties and genotypes (early bloomer varieties) were most resistant for infestation by SBW larvae, such as(G.76, G.89, G.80 and G.31), while (late bloomer varieties and genotypes) were the most susceptible, such as (G.45, Bahtim 101, G.85, G.88, G.75 and G.70) (Hassanein et al., 1969; AbdelRahim et al., 1976; Abdel-Bary et al., 1980;; Abou Toor et al., 1989; AbdelHalim et al., 2000; and El-Mezayyen, 2004). So, Al-Ameer et al. (2010) found Karshensky 2 and G.70 (late bloomer) were most susceptible varieties, while Pima S6 x G.89 and Seuvin (early bloomer variety) were the most resistant during 2007 and 2008 seasons at Kafr El-Sheikh region. 
Table (2): Weekly mean number of infested green bolls by spiny bollworm, E. insulana (Boisd.) per $\mathbf{5 0}$ green bolls during season 2013.

\begin{tabular}{|c|c|c|c|c|c|c|}
\hline Date & G.86 & $\begin{array}{c}\text { Pima S6 x } \\
\text { G.77 } \\
\end{array}$ & G.92 & G.94 & $\begin{array}{l}\text { G.86 X } \\
10 / 229 \\
\end{array}$ & G.88 \\
\hline $25 / 7$ & 0 & 0 & 0 & 0 & 0 & 0 \\
\hline $1 / 8$ & 0 & 0 & 0 & 0 & 0 & 0 \\
\hline $8 / 8$ & 2 & 0 & 0 & 0 & 0 & 0 \\
\hline $15 / 8$ & 5 & 1 & 1 & 2 & 3 & 1 \\
\hline $22 / 8$ & 4 & 5 & 3 & 2 & 8 & 4 \\
\hline $29 / 8$ & 2 & 3 & 1 & 2 & 5 & 0 \\
\hline $5 / 9$ & 5 & 4 & 4 & 1 & 3 & 3 \\
\hline $12 / 9$ & 1 & 4 & 3 & 2 & 2 & 4 \\
\hline $19 / 9$ & 1 & 1 & 4 & 2 & 3 & 2 \\
\hline $26 / 9$ & 0 & 1 & 3 & 2 & 1 & 3 \\
\hline $3 / 10$ & 2 & 4 & 3 & 2 & 3 & 2 \\
\hline $10 / 10$ & 4 & 8 & 6 & 4 & 6 & 4 \\
\hline $17 / 10$ & 8 & 16 & 12 & 8 & 12 & 8 \\
\hline $24 / 10$ & 6 & 10 & 8 & 6 & 8 & 6 \\
\hline Total & 40 & 57 & 48 & 33 & 54 & 37 \\
\hline G.M. & 2.86 & 4.07 & 3.43 & 2.36 & 3.86 & 2.64 \\
\hline
\end{tabular}

Gossypol concentration in green boll wall during the two seasons 2012 and 2013:

Results in Table (3) show that the means of gossypol in green boll wall of varieties and genotypes of cotton were $(1.78,1.33,1.44,0.88,1.75$ and 1.16\%) for G.86, Pima S6 x G.77, G.92, G.94, G.86 x 10/229 and G.88, respectively. The highest average of gossypol \% during 2012 season was estimated in G.86 and G.86 x 10/229 (1.78 and 1.75\%), respectively. While, the lowest was in G.94 and G.88 (0.88 and $1.16 \%)$, respectively.

Data presented in Table (3) indicate that the means of gossypol\% in green boll wall in season 2013 were $(1.77,1.31,1.43,0.93,1.74$ and 1.15\%) for the same varieties and genotypes of cotton, respectively. The highest average of gossypol\% during this season was estimated in G.86 and G.86 x $10 / 229(1.77$ and $1.74 \%)$, respectively. While, the lowest was in G.94 and G.88 (0.93 and $1.15 \%)$, respectively.

Gossypol percentage from mean data during two seasons:

In both seasons (2012 and 2013) the averages of gossypol percentage as shown in Table (3) were $(1.78,1.32,1.44,0.91,1.75$ and $1.16 \%)$. The highest and lowest averages of gossypol\% during the two both seasons, (1.78 and $1.75 \%)$ and $(0.91$ and $1.16 \%$ ) for (G.86 and $G .86 \times$ 10/229) and (G.94 and G.88), respectively. Previous results mean that infestation of green bolls, correlated with gossypol \%, so it showed that the highest varieties and genotypes of gossypol \% was lowest in infestation by SBW larvae. While, the lowest varieties and genotypes of gossypol \% was the highest infestation by SBW larvae. Results in Table (4) showed significant differences between varieties $\left(0.685^{\star *}\right)$, but it was insignificant differences between years $\left(0.001^{\mathrm{NS}}\right)$ and between (varieties and years) was $\left(0.001^{\mathrm{NS}}\right)$. 
J. Plant Prot. and Path., Mansoura Univ., Vol.6 (1), January, 2015

3-4 
Data in Table (5) show that the correlation coefficient was negative and significant between infestation green bolls and concentration of gossypol $\left(-0.451^{*}\right)$.

Table (5): The correlation coefficient among all studied characters

\begin{tabular}{|l|c|c|c|c|c|}
\hline \multicolumn{1}{|c|}{ Traits } & Infestation \% & Gossypol \% & $\begin{array}{c}\text { Bollwall } \\
\text { thickness(mm) }\end{array}$ & $\begin{array}{c}\text { Weightof bolls } \\
(\mathbf{g})\end{array}$ & Yield (g) \\
\hline Infestation\% & - & $-0.451^{*}$ & $-0.487^{* *}$ & $-0.085^{\text {NS }}$ & $-0.540^{* *}$ \\
\hline Gossypol \% & & - & $-0.466^{* *}$ & $0.307^{\text {NS }}$ & $0.222^{\text {NS }}$ \\
\hline $\begin{array}{l}\text { Boll wall } \\
\text { thickness (mm) }\end{array}$ & & & - & $0.194^{\text {NS }}$ & $-0.129^{\text {NS }}$ \\
\hline Weight of bolls (g) & & & & - & $0.613^{* *}$ \\
\hline Yield (g) & & & & & - \\
\hline
\end{tabular}

These previous results were in agreement with Al-Ameer et al. (2010) who found that the correlation between concentration of gossypol and insect infestation was significant and negative $\left(-0.551^{*}\right)$. Also, Abou-Toor (1986) estimated that the correlation was negative and significant between resistance to bollworms infestation and number of glands $/ \mathrm{cm}^{2}$ of boll and total gossypol contents. According to Bottger (1964) gossypol is also toxic to cotton bollworm, furthermore Shaver and Lukefahr (1969) showed the effect of gossypol (concentration) on bollworms and budworms. Also, Vilkova (1989) reported that even though high gossypol lines had weight when compared to those on low gossypol lines, the larval from the high gossypol lines that survived had a higher pupal weight because of their apparent resistance to gossypol, but fecundity of these survivors was significantly reduced. Abd El-Hamid and Helw (1973) and Meisner et al. (1977) suggested that gossypol content may be one of the factors associated with resistance to cotton leafworm, so these genotypes can be used as a stock in breeding programs or using in the direct and general agriculture.

Green boll wall thickness $(\mathrm{mm})$ during the two seasons 2012 and 2013:

Results in Table (3) show that the means of green boll wall thickness of 6 varieties and genotypes of cotton, were $(2.75,2.37,2.08,2.83,3.02$ and $2.82 \mathrm{~mm}$ ) for G.86, Pima S6 x G.77, G.92, G.94, G.86 x 10/229 and G.88, respectively. The highest mean of green boll wall thickness during this season was estimated in G.86 x 10/229 and G.94 (3.02 and $2.83 \mathrm{~mm}$ ), respectively. While, the lowest was in G.92 and Pima S6 x G.77 (2.08 and $2.37 \mathrm{~mm}$ ), respectively.

Data presented in Table (3) indicate that the means of green boll wall thickness were $(2.78,2.38,2.05,2.81,3.06$ and $3.06 \mathrm{~mm})$ for the same varieties and genotypes of cotton, respectively. The highest mean of green boll wall thickness was estimated in G.86 x 10/229 and G.88 (3.06 and 3.06 $\mathrm{mm}$ ), respectively. While, the lowest was in G.92 and Pima S6 x G.77 (2.05 x $2.38 \mathrm{~mm}$ ), respectively.

Green boll wall thickness from mean data during both seasons:

In both seasons (2012 and 2013), the green boll wall thickness from mean data (Table 3) were $(2.77,2.38,2.07,2.82,3.04$ and $2.94 \mathrm{~mm}$ ). The highest and lowest average means of green boll wall thickness from mean data over both seasons (3.04 and $2.94 \mathrm{~mm}$ ) and $(2.07$ and $2.38 \mathrm{~mm}$ ) for (G.86 x 10/229 and G.88) and (G.92 and Pima S6 x G.77), respectively. 
Results in Table (4) reveale that the significant difference among varieties was $\left(2.146^{* *}\right)$, but it insignificant differences between years $\left(0.001^{\mathrm{NS}}\right)$ and between (varieties and years) $\left(0.002^{\mathrm{NS}}\right)$. Also, data in Table (5) show that the value of correlation was negative significant $\left(-0.485^{* *}\right)$ between infestation of green boll by larvae SBW and green boll wall thickness.

Boll weight $(\mathrm{g})$ during the two seasons 2012 and 2013:

Results in Table (3) show the means of boll weight of 6 varieties and genotypes of cotton were $(13.81,13.66,14.07,15.59,17.50$ and $12.87 \mathrm{~g})$ for G.86, Pima S6 x G.77, G.92, G.94, G.86 x 10/229 and G.88, respectively. The highest means of boll weight were estimated in G.86 x 10/229 and G.94 (17.50 and $15.59 \mathrm{~g})$, respectively. While, the lowest ones were in G.88 and Pima S6 x G.77 (12.87 and $13.66 \mathrm{~g}$ ), respectively.

The data presented in Table (3) indicated that the means of boll weight, were $(13.22,13.68,12.25,12.29,14.83$ and $11.74 \mathrm{~g})$ for the same varieties and genotypes of cotton, respectively. The highest means of boll weight were estimated in G.86 x 10/229 and Pima S6 x G.77 (14.83 and $13.68 \mathrm{~g})$, respectively. While, the lowest ones were in G.88 and G.92 (11.74 and $12.25 \mathrm{~g}$ ), respectively.

Boll weight from mean data during both seasons:

In both seasons (2012 and 2013), the boll weight from mean data (Table $3)$, were $(13.52,13.67,1.16,13.94,16.17$ and $12.31 \mathrm{~g})$. The highest and lowest average of boll weight were (16.17 and $13.94 \mathrm{~g})$ and $(12.31$ and $13.16 \mathrm{~g})$ for (G.86 x 10/229 and G.94) and (G.88 and G.92), respectively. The results presented in Table (4) showed significant differences among varieties $\left(10.02^{\star *}\right)$, so, it was between years $\left(22.56^{\star *}\right)$, but it was insignificant difference between years and varieties $\left(2.37^{\mathrm{NS}}\right)$. Previous results in Table (5) showed the values of correlation was negative insignificant $\left(-0.045^{\mathrm{NS}}\right)$ between infestation green bolls and boll weight.

Yield $/ \mathrm{m}^{2}$ of varieties and genotypes of cotton during the two seasons 2012 and 2013:

Results in Table (3) show that the means of yield of 6 varieties and genotypes of cotton were $(825,460,910,800,920$ and $765 \mathrm{~g})$ for G.86, Pima S6 x G.77, G.92, G.94, G.86 x 10/229 and G.88, respectively. The highest means of yield were estimated in G.86 x 10/229 and G.92 (920 and $910 \mathrm{~g}$ ), respectively. While, the lowest ones were Pima S6 x G.77 and G.88 (460 and $675 \mathrm{~g})$, respectively.

Data presented in Table (3) indicate that the means of yield, were $(303.33,445.00,363.33,216.67,513.33$ and $215.00 \mathrm{~g})$ for the same varieties and genotypes of cotton, respectively. The highest means of yield during this season was estimated in G.86 x 10/229 and Pima S6 x G.77 (513.33 and $445.00 \mathrm{~g}$ ), respectively. While, the lowest ones were in G.88 and G.94 (215.00 and $216.67 \mathrm{~g})$, respectively.

Yield $/ \mathrm{m}^{2}$ of varieties and genotypes of cotton from mean data during both seasons:

In both seasons (2012 and 2013), the yield $/ \mathrm{m}^{2}$ from mean data (Table 3) were $\left(564.17,452.50,636.67,508.34,716.67\right.$ and $\left.445.00 \mathrm{~g} / \mathrm{m}^{2}\right)$. The highest and lowest average of yield $/ \mathrm{m}^{2}$ from mean data during both seasons were $\left(716.67\right.$ and $\left.636.67 \mathrm{~g} / \mathrm{m}^{2}\right)$ and $\left(445 / 00\right.$ and $\left.452.50 \mathrm{~g} / \mathrm{m}^{2}\right)$ for $(\mathrm{G} .86 \mathrm{x}$ 
10/229 and G.92) and (G.88 and Pima S6 x G.77), respectively. Data in Table (5), show the value of correlation was negative insignificant $\left(-0.263^{\mathrm{NS}}\right)$ between infestation green bolls and yield $/ \mathrm{m}^{2}$. But, Al-Ameer et al. (2010) found the value of correlation was negative significant between infestation and lint yield $/ \mathrm{m}^{2}\left(-0.684^{*}\right)$.

\section{REFERENCES}

Abdel-Bary, A.A.; M.A. Omer and M.M. Shahbander (1980). Evaluation of bollworm resistance in some Egyptian cotton cultivars and strains. Alex. J. Agric. Res., 28(1): 91-96.

Abdel-Halim, A.; K.A.M. El-Khawass and H.A.F. Salem (2000). Boll infestations with pink bollworm Pectinophora gossypiella (Saund.) and spiny bollworm (Earias insulana (Boisd.) on certain cotton varieties in Damietta Governorate. Al-Azhar J. Agric. Res., 31: 149155.

Abdel-Hamid, A.M. and M.R. Helw (1973). Cotton leaf worm on different genotypes of cotton. Cott. Gr. Rev., 50(4): 338.

Abd El-Rahim, W.A.; S.M.I. Metwally and F. El-Dakroury (1976). Susceptibility of some Egyptian cotton varieties to the infestation by Pectinophora gossypiella (Saund.) and Earias insulana (Boisd.). J. Agric. Res. Tanta Univ., 2(2): 332-338.

Abou-Toor, H.B. (1986). Genetical studies on resistance to insects in Egyptian cotton. Ph.D. Thesis, Fac. Agric., Tantna Univ., 210 pp.

Abou-Toor, H.B.; M.M. Abou-Kahla; A.A.S. El-Zanan and I.A.I. Helal (1989). The susceptibility of nine Egyptian cotton cultivars to infestation with cotton insect pests. The $7^{\text {th }}$ Arab Pesticide Conference, Tanta Univ., Sept., 11-12.

Al-Ameer, M.A.; M.A. Abd El-Salam; W.M.B. Yehia and I.A.I. Saad (2010). Evaluation of some cotton genotypes for ability to infestation tolerance to bollworm for improving of some important economical characters. J. Agric. Res., Kafr El-Sheikh Univ., 36(2): 147-172.

Bottger, G.T. (1964). Relation of gossypol content of cotton plants to insect resistance. J. Econ. Entomol., 57: 283-285.

El-Mezayyen, G.A. (2004). Evaluation of some Egyptian cotton varieties of infestation of piercing sucking insects, cotton leafworm and bollworms at Kafr El-Sheikh region. J. Agric. Sci., Mansoura Univ., 29(1): 433441.

Fasell, M.D. (1977). Investigation on the biology, ecology and control of Earias insulana (Boisd) (Noctuidae). Entomol. Phytopath. Appl., 43: 39-54.

Hassanein, M.H.; M. Hafez and G.A. Rizk (1969). The susceptibility of certain cotton varieties to bollworms infestation. Bull. Soc. Ent. Egypte, 53: 261-269.

IRRI (1996). Standard evaluation system for rice INGER Prog. International Rice Research Institute July Edition, p. 12, 13, 43, 47. 
Meisner, J.; M. Zur; E. Kabonci and K.R.S. Ascher (1977). Influence of gossypol content of leaves of different cotton strains on the development of Spodoptera littoralis larvae. J. Econ. Entomol., 70(6): 714-716.

Shaver, T.N. andM.J. Lukefahr (1969). Effects of flavonoids pigments and gossypol on growth and development of the bollworm, tobacco budworm, and pink bollworm. J.Econ. Entomol., 62: 643-646.

Vilkova, N.A. (1989). Effect of cotton cultivars with high content of gossypol on development of the cotton bollworm Heliothis armigra ( $\mathrm{Hbn}$ ) (Lepidoptera: Noctuidae). J. Econ. Entomol. Rev., 68: 129-137.

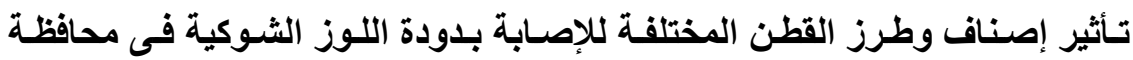
كفرالشيخ

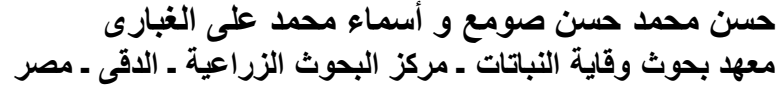

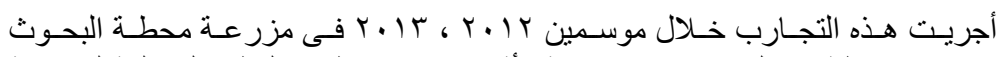

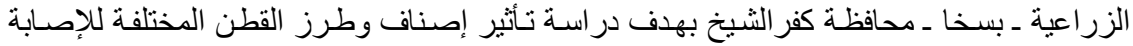

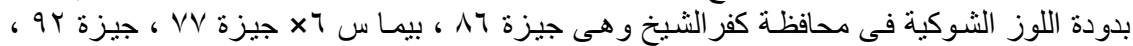

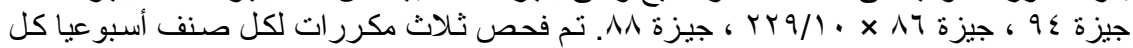

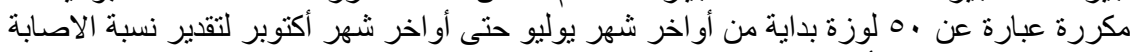

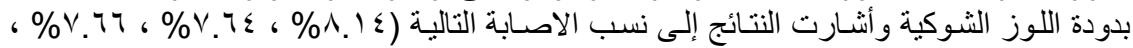

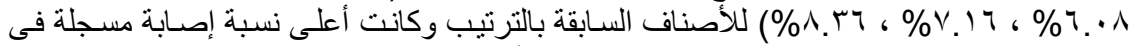

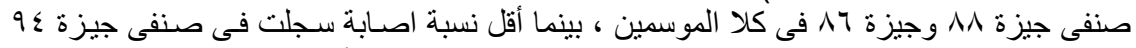

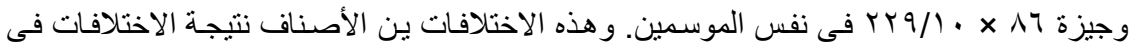

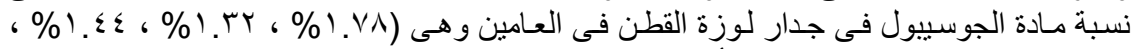

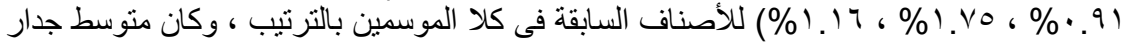

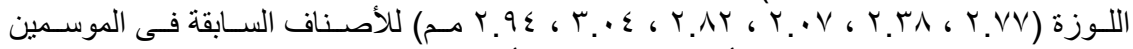

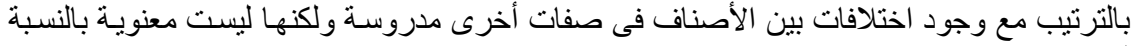
للإصنابة. 


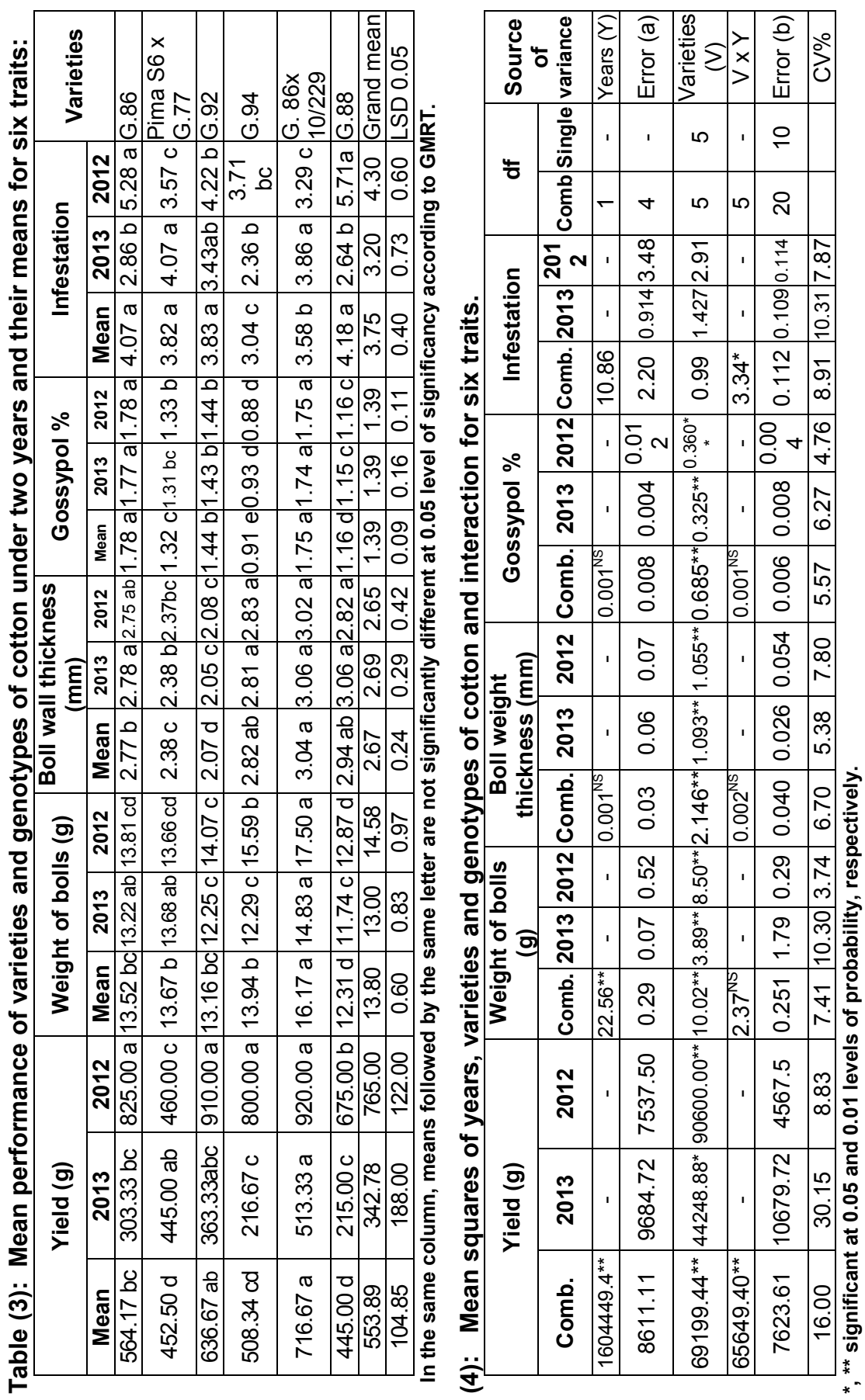